\section{Pelaksanaan Pembangunan Jalan Titian Beton Teluk Ujung Benteng Pulau Bromo}

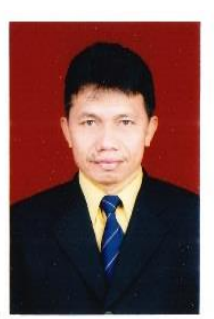

\section{Ir. Ahmad Rubani}

Penulis bekerja dalam bidang konstruksi dan sekarang menjabat sebagai direktur di perusahaan PT. Bina Sarana Bersama. buletinppi@ulm.ac.id
Dalam rangka pelaksanaan proyek peningkatan jalan beton titian bromo teluk ujung benteng adalah merupakan proses peningkatan jalan yang dilaksanakan pemerintah kota Banjarmasin yang bertujuan untuk meningkatkan infrastruktur yang ada didaerah teluk ujung benteng pulau bromo. Proses kerja yang dilakukan dalam proyek ini adalah berupa mengganti titian jalan yang sudah ada di pulau bromo yang masih berupa titian ulin menjadi titian beton untuk meningkatkan keamanan dan transportasi permanen bagi masyarakat. Kegiatan pekerjaan peningkatan jalan dilakukan sesuai dengan spesifikasi yang tertuang dalam pedoman pelaksanaan agar dicapai tepat waktu, biaya dan mutu.

Kata Kunci : Proyek, Peningkatan Jalan.

www.buletinppi.ulm.ac.id

\section{Pendahuluan}

Seiring meningkatnya perkembangan suatu daerah dan untuk meningkatkan taraf hidup serta untuk memajukan perekonomian, diperlukan prasarana perhubungan yang fungsinya sangat penting dan vital, baik itu perhubungan darat maupun laut. Dalam hal ini sarana perhubungan dan pengembangan jaringan jalan adalah sangat penting untuk menunjang perkembangan di sektor-sektor lainnya, dengan demikian perlu dipikirkan untuk meningkatkan dan membangun jalan guna meningkatkan kemudahan akses bagi suatu daerah atau wilayah.

Dengan lancarnya sarana perhubungan pada suatu wilayah atau daerah akan berdampak pada pesatnya pertumbuhan perekonomian wilayah tersebut, karena sistem mobilisasi barang dan jasa dapat berjalan lancar dan efisien, serta berguna juga untuk membuka daerah-daerah yang terisolir sekaligus dalam pengembangan wilayah khususnya daerah Pulau Bromo Banjarmasin.

Tujuan pembangunan jalan /titian beton ini adalah untuk meningkatkan prasarana dan sarana daerah setempat yang tadinya hanya berupa titian ulin dengan lebar 1,5 m tanpa adanya pagar pengaman. Selain itu prasarana yang ada sering mengalami kerusakan jadi membuat biaya pemeliharaan yang sangat tinggi. Dengan dibangunnya titian beton selain lebih kuat dan biaya pemeliharan yang kecil, juga dari segi arsitek jelas lebih indah Pengguna jalan juga merasa lebih tenang dan aman.

\section{Hasil Kerja}

\section{Peningkatan Jalan Titian dari Ulin Ke Beton}

Proyek titian beton Teluk Ujung Benteng ini dikerjakan dengan rencana panjang $485 \mathrm{M}$ dan Lebar $2 \mathrm{~m}$. Pekerjaan proyek ini menggunakan pondasi tiang pancang kayu galam panjang $7 \mathrm{~m}$,Pemancangan kayu galam cukup menggunakan alat pancang sederhana (kaki tiga), Poer beton dengan menggunakan besi ulir $\mathrm{D} 16 \mathrm{~mm}$, kolom beton dengan besi ulir $D 19 \mathrm{~mm}$, balok melintang dan memanjang dengan besi ulir D $16 \mathrm{~mm}$, dan lantai menggunakan besi dia $12 \mathrm{~mm}$.

Pada bagian pondasi menggunakan besi dia $16 \mathrm{~mm}$ yang dibentuk sesuai dengan gambar perencanaan dan ditambahkan besi pengaku(penahan geser) dengan besi dia $12 \mathrm{~mm}$ untuk menjaga kelenturan ditempat yang diperlukan/ menyesuaikan dengan gambar rencana (shop drawing), setelah itu dilakukan dilakukan pengecoran pada pondasi dengan selimut beton $5 \mathrm{~cm}$ (sesuai standar SNI). Pada Proses pengecoran besi pondasi ditutup terlebih dahulu dengan bekisting, bekisting disini dibuat khusus dari plat besi karena kondisi lapangan yang terletak di tepi sungai besar, dimana arus airnya cukup deras dan disekeliling pondasi yang akan dicor ditutup oleh coverdam (coverdam disini juga dibuat khusus karena dari plywood 12 $\mathrm{mm}$ karena kondisi air dan medan lapangan) agar pondasi yang akan di cor dalam keadaan kering dan untuk tindakan lanjutan apabila lokasi pengecoran belum kering digunakan pompa air untuk menyedot air keluar dari lokasi pengecoran.

Proses pembesian selanjutnya pada bagian kolom digunakan besi ulir D $19 \mathrm{~mm}$ dengan tinggi sesuai gambar, dengan varian atau bervariasi sesuai kondisi tinggi elevasi tanah setiap titik dan dipasangi dengan sengkang besi dia $12 \mathrm{~mm}$ dengan jarak $12 \mathrm{~cm}$. Besi kolom ditutup dengan bekisting papan/ kayu lalu di cor dengan tebal selimut $5 \mathrm{~cm}$ (sesuai standard SNI). Pengecoran kolom juga dilakukan proses pengeringan lokasi dan pemasangan coverdam seperti pada pondasi di lokasi yang diperlukan atau terkena air sungai.

Proses Pembesian selanjutnya pada bagian balok melintang dengan besi D $16 \mathrm{~mm}$ yang dibentuk sesuai dengan gambar perencanaan (shop drawing) dan ditambahkan besi pengaku(penahan geser) dengan besi dia 
$12 \mathrm{~mm}$ untuk menjaga kelenturan ditempat yang diperlukan/menyesuaikan dengan gambar.

Proses Pembesian selanjutnya dilakukan pada bagian dilatasi yang dibentuk sesuai gambar perencanaan dengan besi $D 16 \mathrm{~mm}$ dan ditambah besi pengaku(penahan geser) dia $12 \mathrm{~mm}$ untuk menjaga kelenturan. Penempatan besi diletasi dipasang setiap jarak $15 \mathrm{~m}$ pada jalan titian beton. Proses Pembesian Selanjutnya dilakukan pada bagian lampu yang dibentuk sesuai dengan gambar perencanaan (shop drawing) dengan besi D $16 \mathrm{~mm}$ ditambah dengan besi pengaku(penahan geser) dia $12 \mathrm{~mm}$ untuk menjaga kelenturan. Penempatan besi lampu dipasang setiap jarak $30 \mathrm{~m}$ padan titian beton.

Pembesian selanjutnya pada besi balok memanjang dengan D $16 \mathrm{~mm}$ yang dipasang dengan sengkang balok dia $12 \mathrm{~mm}$.

Pada pembesian lantai menggunakan besi $12 \mathrm{~mm}$ memanjang dan melintang dengan jarak $10 \mathrm{~cm}$.

Perlu diketahui bahwa proyek titian teluk ujung benteng ini pembangunannya persis di tepi sungai Barito yang cukup besar dan lebar, dengan lokasi untuk tempat penumpukan material yang terbatas, sehingga perlu penanganan khusus yang efektif dan efisien dalam artian penanganan spesial untuk mempermudah mobilisasi alat dan material.

Semua kegiatan mobilisasi peralatan dan material hanya bisa melalui sungai dalam artian menggunakan transportasi air (perahu). Untuk mobilisasi material semen, pasir dan batu split dari supplier bisa langsung diantar ke lokasi proyek, sedangkan material besi yang dibeli dikirim ke workshop dulu, dan di produksi di workshop baru setelah itu dikirim ke lokasi, hal ini dilakukan untuk efesiensi waktu dan biaya pada saat mobilisasi.

Dari pengamatan penulis, sistem manajemen logistik yang dijelaskan lebih efektik, karena kemajuan proyek selalu sesuai jadwal yang direnacakan. Dalam pelaksanaan untuk menjaga mutu beton selalu dilakukan pembuatan sample kubus beton dengan didahului periksaan sample slump, disetiap saat pengecoran, dan sehari setelah itu kubus dibuka dan sample direndam di lokasi dalam jangka waktu 2-3 hari langsung dibawa ke workshop supaya saat di lakukan uji kuat tekan mutu beton tetap terjaga.

\section{Jalan Titian Beton}

Dengan dibangunnya titian permanen dari beton ini diharapkan manfaat yang sebesar besarnya dapat dinikmati oleh masyarakat setempat. Sesuai dengan konsep kepala daerah dimana pembangunan titian beton tersebut nantinya akan menjadi tempat salah satu wisata susur sungai di Banjarmasin.

Pada proyek ini mutu beton dan besi menggunakan standard (referensi) SNI, jadi setiap pelaksanaan pengecoran selalu dibuatkan kubus sebagai bahan untuk melakukan test kuat tekan beton, sedangkan mutu besi dilakukan test kuat tarik sesuai standard SNI.

Adanya pembangunan titian ini juga sangat penting untuk dilaksanakan oleh pemerintah setempat untuk mempermudah transformasi masyarakat dan pemerintah untuk menciptakan rasa aman dalam rangka peninjuan / kunjungan - kunjungan formal atau non formal karena dibangun dengan bangunan yang permanen.

Dari hasil pengamatan penulis lokasi pembangunan titian tersebut berlokasi diseberang sungai atau berada di salah satu pulau yang terpisah dengan daratan wilayah lain sehingga masyarakat setempat jika bepergian ke kota atau melakukan kegiatan diluar pulau tersebut harus menggunakan transportasi sungai. Jadi menurut penulis perlu perencanaan yang matang agar dibangun jembatan penghubung yang permanen.

\section{Gambaran Pekerjaan 0\% dan Setelah Pengerjaan}

Sebelum proyek di kerjakan titian jalan pada pulau bromo hanya sebatas titian ulin yang cukup memprihatinkan untuk tingkat keamanan dan kenyamanan bagi pengguna jalan yang dapat dilihat pada Gambar 1. Pada Gambar 2, 3 dan 4 diperlihatkan gambar proyek yang sudah dikerjakan sampai pada penyelesaian struktur yang terdiri dari poer, kolom dan balok melintang, pengerjaan selanjutnya akan dilanjutkan pembuatan pagar untuk meningkatkan keamanan pengguna transportasi diwilayah pulau bromo.

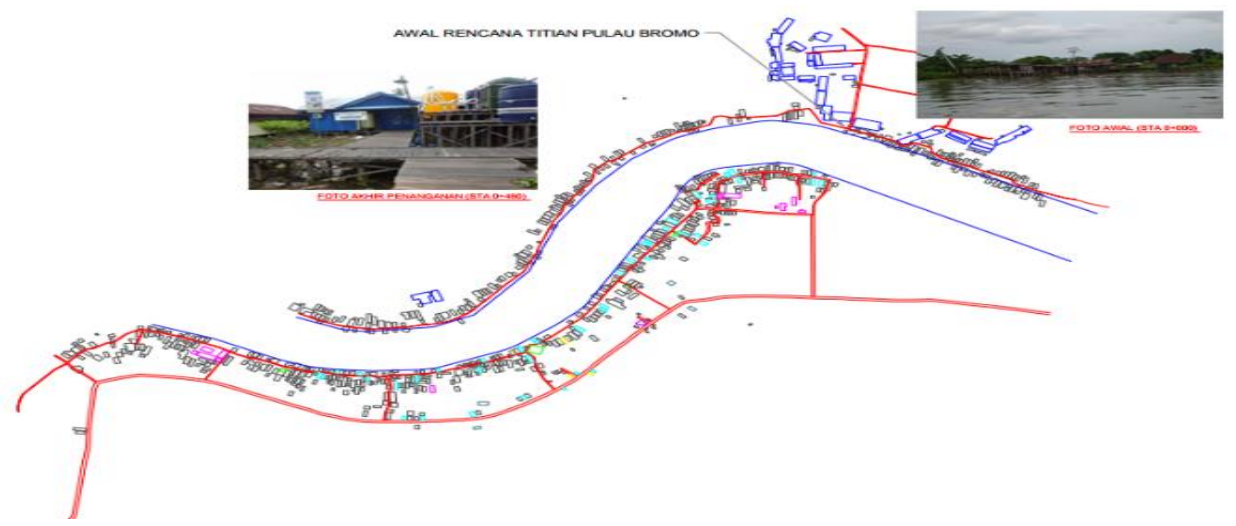

Gambar 1. 0\% Pekerjaan 


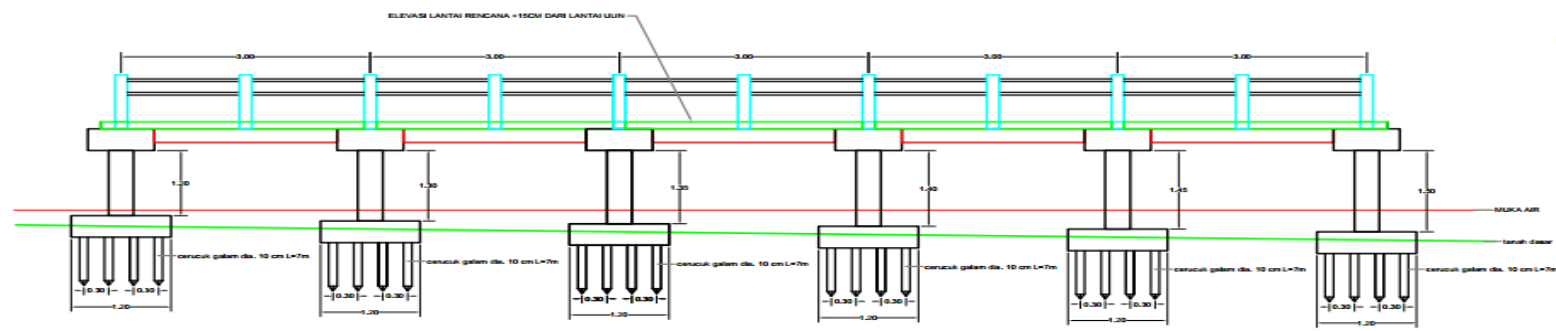

TAMPAK MEMANJANG

Gambar 2. Tampak Memanjang

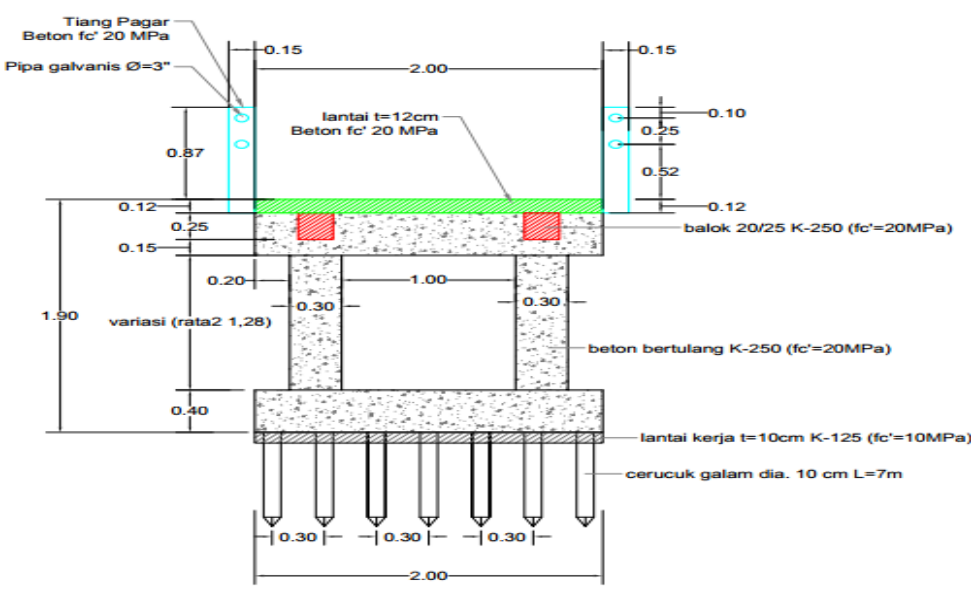

TAMPAK MELINTANG

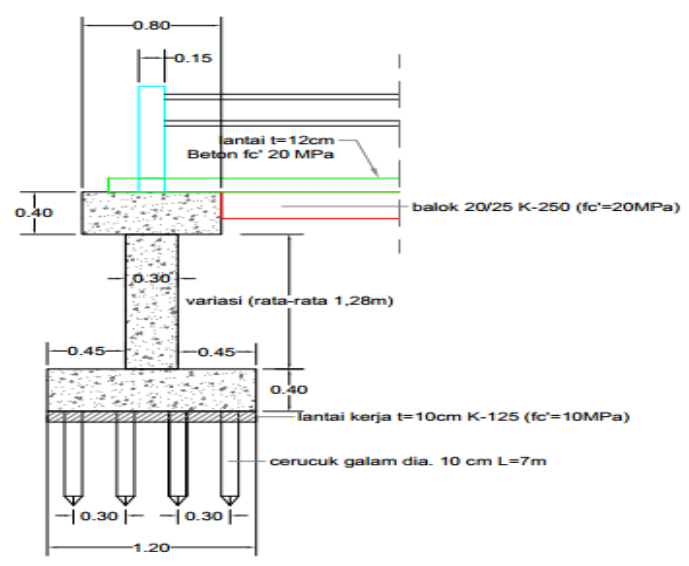

TAMPAK MEMANJANG

Gambar 3. Tampak Memanjang dan Melintang
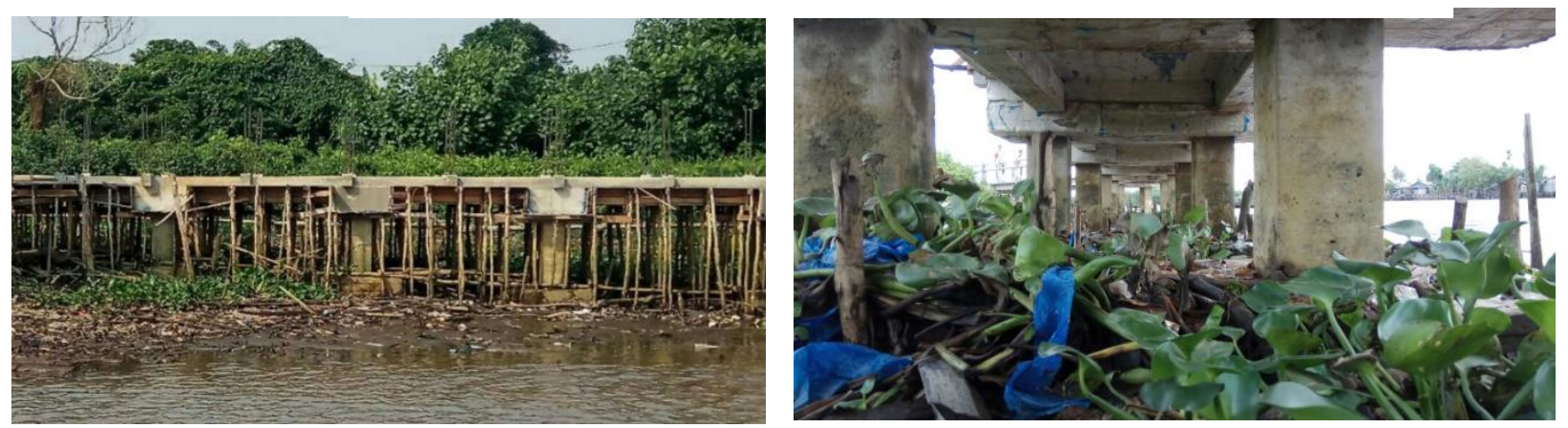

Gambar 4. Foto Pekerjaan Tampak Bawah dan Memanjang

Kesimpulan

Dari hasil analisis pengerjaan proyek dapat disimpulkan bahwa:

1. Pekerjaan ini bermanfaat sebagai infrastruktur permanen yang berguna membantu masyarakat setempat melakukan aktivitas ekonomi. 
2. Kegiatan proyek memberikan manfaat rasa aman masyarakat pengguna jalan yang sebelumnya masih hanya titian ulin yang kondisinya memprihatinkan.

3. Melakukan studi kelayakan yang lebih matang untuk antisipasi masalah yang akan terjadi dikemudian hari.

\section{Ucapan Terimakasih}

Ucapan terima kasih pertama sekali kami ucapkan syukur Alhamdulillah atas rahmat dan hidayah Allah SWT maka makalah ini dapat kami buat, dan kepada bapak pembimbing kami bapak Ir. Darmansyah Tjitradi, ST., MT., IPM., ASEAN Eng.

\section{Referensi}

1. ....., 2017, UU No. 2 Tahun 2017 tentang Jasa Konstruksi.

2. ....., 2010, Perpres Nomor 54 Tahun 2010 Tentang Pengadaan Barang/Jasa Pemerintah beserta perubahan dan aturan turunannya.

3. ....., 2000, PP No.29/2000 tentang Penyelenggaraan Jasa Konstruksi.

4. ....., 2017, Dokumen Kontrak Nomor: 03/DPUPRBJL\&PJU-PPK-PJ.P2/V/2017 tanggal 29 Mei 2017 Pekerjaan Peningkatan Jalan Paket 2 (Peningkatan Titian Jalan Teluk Ujung Benteng (Pulau Bromo)). 